\title{
Europa i el cristianisme: 500 anys del luteranisme $(1517-2017)^{1}$
}

\author{
Karine Rivas i Guzmán* \\ Conrad Vilanou Torrano**
}

Recepció original: 06 de febrer de 2018

Acceptació: 23 de maig de 2018

Publicació: 20 de juliol de 2018

És ben sabut que, segons la tradició, el 31 d'octubre de 1517, Martí Luter -un frare agustí que va viure entre 1483 i 1546- va penjar les noranta cinc tesis sobre les indulgències a l'església del castell de Wittenberg. Avui es reconeix que molt probablement no es va produir aquest fet -és a dir, no es van penjar materialment- però sí que és cert que el text original en llatí va ser traduït a l'alemany ben aviat i va circular ràpidament entre la població. La impremta havia estat un invent recent, de manera que les idees luteranes van tenir una gran difusió i van significar un nou trencament dins del cristianisme, després del cisma d'Orient del segle XI. Després d'aquella ruptura, I'Església catòlica va experimentar una segona escissió, en dividir-se entre el Papat i el món germànic, que va optar per la Reforma luterana. Enmig d'aquests dos mons, va aparèixer el 1534 l'anglicanisme, una mena de via mitjana entre els catòlics i els luterans, sense perdre de vista que les idees luteranes de Calví, autor de la Institució de la religió cristiana, que es va forjar entre 1536 i 1559, van generar un moviment que es va assentar a Ginebra i que va influir al centre d'Europa primer i, més tard, als Estats Units d'Amèrica. Amb aquests antecedents, tot sembla indicar que Europa -que per molts era inseparable de la idea de Cristiandat- es va fragmentar per sempre més, de manera que perdia la unitat anterior i, alhora, la Reforma es presentava com una alternativa al catolicisme, una mostra del caràcter dialèctic de l'esdevenir continental.

No hi ha dubte que la Reforma luterana, a la qual va respondre l'Església catòlica amb el Concili de Trento (1545-1563), constitueix un dels referents d'una modernitat que no només ha estat científica (Newton, Galileu), filosòfica (Descartes) i literària (Montaigne), sinó també teològica amb la Reforma luterana, econòmica (amb l'ascens de la burgesia i del capitalisme) i pedagògica, en bona part gràcies a la renovació humanística que va sorgir a Itàlia (Valla) i que es va estendre per tot el continent (Erasme de Rotterdam, Joan Lluis Vives). Ben mirat, la divisió entre catòlics i luterans va comportar importants repercussions pedagògiques des del moment que, si la Ratio Studiorum dels jesuïtes, definida el 1599, es pot entendre com una resposta educativa per frenar la difusió de les idees luteranes, no és menys veritat que en els ambients protestants -que van ser receptius a les novetats filològiques de l'humanisme erasmista- es va generar una important reforma dels estudis d'educació secundària dirigida per Philipp Melanchton, considerat el Praeceptor Germaniae (Monreal Pérez, 2017). No debades, el professor

(1) La recerca que ha donat lloc a aquests resultats ha estat impulsada per RecerCaixa.

${ }^{*}$ ) Professora del Departament de Teoria i Història de l'Educació de la Universitat de Barcelona i membre del GREPPS (Grup de Recerca en Pensament Pedagògic i Social). S'ha especialitzat en els estudis comparatius de l'educació des d'una perspectiva política i internacional. Adreça electrònica: krivas@ub.edu

$\left(^{* *}\right)$ Professor del Departament de Teoria i Història de l'Educació de la Universitat de Barcelona i investigador principal del GREPPS (Grup de Recerca en Pensament Pedagògic i Social). S'ha especialitzat en l'estudi dels conceptes, discursos i narratives pedagògiques. Adreça electrònica: cvilanou@ub.edu 
Buenaventura Delgado -que va fomentar la Història de l'Educació des de la seva càtedra a la Universitat de Barcelona- va sintetitzar la pedagogia de la Reforma i de la Contrareforma en un llibre ben aclaridor i sistemàtic (Delgado, 2002).

Altrament, Comenius -que ha estat considerat l'artífex de la didàctica moderna i un precursor de la pedagogia social amb el seu ideal pansòfic de caire europeista i universalista- va sorgir en els ambients reformats, que són una conseqüència dels nuclis luterans. Amb altres paraules, la modernitat pedagògica -la gènesi de la qual és molt anterior a la publicació de l'Emili el 1762- deu moltes coses a la teologia, als debats que en el camp de la fe es van donar entre luterans i catòlics, a les actituds jansenistes i als solitaris de Port-Royal. Ja des de les pàgines de Temps d'Educació, Javier Pamparacuatro Martín (núm. 35, 2008) es feia ressò d'aquesta dinàmica històrica, que situava l'origen de la pedagogia moderna en el deixant de la lògica de Port-Royal, sempre distant dels jesuïtes i propera als pensaments de Blaise Pascal. En aquest punt, podem esmentar el dossier que «Sobre els orígens de la Modernitat pedagògica» es va publicar també a les pàgines de Temps d'Educació (núm. 46, 2014), en què diversos autors van revisar les aportacions de Montaigne, Descartes i Rousseau a la ciència pedagògica.

No obstant, en aquella ocasió -i per l'extensió del dossier- es va deixar de banda la figura de Luter i l'impacte de les idees reformistes que ara s'aborden en un procés de llarga duració en aquest número, ja que els autors d'aquest dossier pouen en les fonts del cristianisme com fa el professor Ignasi Boada, de la Universitat Ramon Llull, en I'article sobre «La contribució de I'humanisme cristià en la construcció d'Europa». Si la història de l'educació -segons un esquema que manllevem del professor Octavi Fullates configura a través de conceptes, discursos i narratives no resulta forassenyat presentar el cristianisme a manera de la gran narrativa que, sobre la base semita i clàssica (grega i llatina), ha configurat el fil conductor de la cultura europea i, per extensió, occidental. Així, doncs, resulta del tot lògic que en aquest dossier s'inclogui la reflexió del professor Fullat sobre «Pau de Tars (10-67): em vaig quedar garratibat», que aprofundeix en el paper cabdal de sant Pau per donar a conèixer el missatge de Crist.

Si observem les coses amb atenció, detectem que Europa no s'entén sense la presència del cristianisme, que va sorgir fa dos mil.lennis en una mena de síntesi d'elements semites i clàssics, fins al punt que la novetat del missatge cristià -que gira a l'entorn de Crist, fill de Déu, que després de morir a la creu va ressuscitar- va representar una mena d'escàndol per a la raó humana. Tant és així que el cristianisme -que no ha negat l'argumentació racional, hereva de la lògica clàssica- ha emfasitzat la transcendència de la fe, cosa encara més significativa en el cas de Luter, que va proclamar la importància de l'Escriptura (Sola scriptura) i de la fe (Sola fide), sense oblidar la gràcia (Sola gratia), Crist (Solus Christus) i la glòria a Déu (Soli Deo gloria). Enllà d'aquestes consideracions, en les bases de l'Europa més recent, en la configuració de la idea d'Europa, es detecta un pòsit certament cristià, que va ser secularitzar durant la II.lustració i que va donar peu a l'ideari de la Revolució Francesa (1789) en el trilema de la qual es constata la presència de la fraternitat que no deixa de ser una versió laica de l'amor (charitas) cristià. És obvi que entre el món de l'Edat Mitjana, una autèntica Cristiandat, i la modernitat il.lustrada, cal situar la Reforma luterana que, com assenyala el professor Marco Antonio Coronel Marcos de la Universitat de València, en l'article «La dignitat de l'ésser humà a la llum de la misericòrdia de Déu: Algunes notes sobre la penitència a Luter», va constituir un veritable canvi de paradigma en trencar amb la tradició aristotèlica de 
l'escolàstica medieval. Així es va renovar la teologia amb l'esperit de la filologia, atès que la Reforma va proposar un retorn a les fonts (Ad fontes) del cristianisme, amb la qual cosa el nou paradigma implicava una via filològica enfront de la tradicional via escolàstica. Ara bé, i junt a aquest nou paradigma, no podem oblidar que amb la Reforma van esclatar les guerres de religió que durant els segles XVI i XVII van portar la discòrdia sobre el continent europeu, una situació que no es va aturar fins la pau de Westfàlia (1648) que va posar fi a la guerra dels trenta anys. Un altra manifestació de la història europea que oscil.la entre la pau i la guerra, entre la concòrdia i la bel.ligerància.

Amb tot, i per damunt d'aquestes lluites, es dibuixa un fil conductor que va des del cristianisme, vist com a síntesi dels mons semita, grec i llatí, fins a l'actualitat. S'ha dit (així ho recull Carles d'Habsburg-Lorena en l'epíleg al Ilibre del seu pare) que Europa és el resultat de la fusió de tres pujols, el Gòlgota, l'Acròpolis i la roca Capitolina, tres Ilocs de memòria que marquen el sentit del cristianisme i l'inici de la idea d'Europa. Nogensmenys, aquest esquema triàdic -Jerusalem, Atenes, Roma- ha estat un element recurrent en l'univers mental del professor Octavi Fullat, els treballs del qual sovintegen a les pàgines de Temps d'Educació. En efecte, sobre la base que Europa constitueix un «a priori pedagògic» (Fullat, 2000), va publicar Valores y narrativa. Axiología educativa de Occidente (2005), un llibre ben aclaridor en què situa en el primer concili de Nicea (325 $\mathrm{dC}$ ) el moment crucial de la fusió de les fonts semites i clàssiques amb la novetat cristiana que roman formalitzada en el credo naciancè (Fullat, 2005).

Siguem creients o no, creguts o descreguts, agnòstics o ateus, sembla oportú reconèixer que molts autors -adés i ara- han destacat els vincles entre Europa i el cristianisme a través d'un desenvolupament cultural que ha tingut lloc al llarg de molts segles i que, entre altres mèrits, ha perfilat un estat d'esperit que pot ser un bon antídot per una visió econòmica i tècnica de la nova Europa (Dawson, 1951). Si aquests perills ja es denunciaven fa anys, quan la CECA (1951) va donar lloc a la Comunitat Econòmica Europea (1957), antecedents de la Unió Europea sorgida del tractat de Maastricht (1992), han crescut últimament quan el Banc Central Europeu -com apunta Enrico Letta (2017) - s'ha convertit, després de la crisi financera de 2008, en la salvaguarda d'Europa.

D'aquí la importància de tots aquells que, com va fer Ramon Sugranyes de Franch en una conferència pronunciada el 1985 i publicada tres anys més tard, han presentat la unitat europea com una via espiritual, o, si més no, cultural encara que avui -en un món postmodern i postcristià, altament secularitzat, amb presència de moltes altres religions- la cultura ja no sigui cristiana. A la vista del que diem, Europa no es pot perfilar com una realitat espiritual d'arrel cristiana, per bé que sembla raonable remarcar la significació d'aquesta herència i tradició, perquè «tanmateix hi ha valors comuns -i molt positius- i aquests sí que són d'arrel cristiana: l'empresa de vint segles de cristianisme no s'esborra ni amb un refús deliberat» (Sugranyes de Franch, 1988, p. 16). Per la nostra part, i d'acord amb el professor Fullat, afegim que Europa constitueix una via cultural construïda sobre la triple matriu semita, hel.lènica i llatina que, sintetitzada en el cristianisme a Nicea, ha fornit el contingut del currículum escolar durant segles, amb la qual cosa aquesta via cultural esdevé una via pedagògica que el luteranisme va contribuir a fer créixer directament (el 1523 Luter va dirigir una petició als magistrats de totes les ciutats alemanyes per tal que construïssin i mantinguessin escoles cristianes) o bé, de manera indirecta, per la reacció catòlica amb la creació de diverses ordes religioses dedicades a l'ensenyament, entre les que destaquen els jesuïtes (1540) i els escolapis 
(1597). Tampoc es pot oblidar la Companyia de Maria, una de les primeres congregacions dedicada a l'ensenyament de les noies que, sobre una base humanista, va ser promoguda per Joana de Lestonnac al començament del segle XVII (1607-1609).

En aquest punt, es pot afegir que, al costat d'aquesta línia pedagògica d'ascendència humanista, trobem un altre deixant, el que prové de la II.lustració i que, a través dels projectes educatius de la Revolució Francesa (Condorcet, en lloc prioritari) va promoure un ideal de ciutadania que es va estendre gràcies a l'alfabetització i a l'escolarització. De tal faisó que gràcies a la tradició jacobina inherent a l'estat-nació que sorgeix de la Revolució Francesa es van generar un seguit de moviments socialistes, al darrera dels quals es detecta la presència d'elements messiànics amb trets de la tradició judeocristiana que, a través dels processos de secularització, es fan palesos en el missatge del marxisme que, d'acord amb Ernst Bloch, aspira a construir un «Regne de déu sense Déu» (Pellicani, 1990, p. 87). Així, doncs, darrera del marxisme es constata la presència d'elements ideològics que no es poden entendre sense la presència d'un rerefons teològic, amb categories del pensament cristià que va ser secularitzat per Spinoza i els pensadors il.lustrats com ara Lessing que va endegar el projecte de L'educació del gènere humà (1780) sobre la base dels ideals d'humanitat de vocació cosmopolita i universalista. Per tant, l'estat educador sorgit del pensament il.lustrat va assumir una fe pedagògica, de signe secular i intramundà, i així es va contrarestar el paper docent de les esglésies, ja fos catòlica o reformada, tal com palesa la història d'alguns països europeus -per exemple, Hongria- on convivien les escoles catòliques, reformades i jueves, situació que es va estroncar a partir dels anys de la Segona Guerra Mundial.

Indubtablement, Europa constitueix una via pedagògica en consonància amb aquesta idea cultural que enllaça amb la religiositat semítica, la cultura clàssica, la síntesi cristiana, I'humanisme, el segle de les Llums, l'ideari il.lustrat, la modernitat secular, l'estat-nació, etc., en un procés de llarg abast que, segons Sándor Márai, afaiçona una «consciència de missió». I, si es vol també, un «credo» diferent del de Nicea (Márai, 2016, p. 307). D’aquí que Márai -que va viure en carn pròpia els destrets de les dues guerres europees i es va veure obligat a suportar el jou que van significar el nazisme i el comunisme- reclamés que l'Europa econòmica era ben poca cosa, si no anava acompanyada d'aquesta consciència d'una missió que inclou importants dosis d'humanisme (Márai, 2016, p. 307). Es pot afegir que per Márai, d'acord amb Protàgores, el deixant humanista d'Europa representa una cosa ben pregona: que l'ésser humà -i no el Partit únic, la raó d'estat o la Idea messiànica i salvadora- és la mesura de totes les coses (Márai, 2016, p. 277). Al seu entendre, les cambres de gas d'Auschwitz o les foses de Katyn posen de manifest que Europa no ha estat guiada per aquesta concepció humana i humanística sinó per la barbàrie, la qual cosa ha comportat l'anorreament de l'ésser humà a partir de justificacions biopolítiques.

A grans trets, tot fa pensar que Europa es pot entendre des d'un prisma ideològic com una mena de lluita de contraris, una guerra d'eons per dir-ho a la manera orsiana. Més amunt, ja ens hem referit al binomi catolicisme i luteranisme i, igualment, a la tensió entre la pau i la guerra. Tampoc podem deixar de banda la tensió entre l'Europa cristiana i la secularitzada, entre la creient i l'agnòstica, entre la confessional i l'atea. Tal situació no pot sobtar, més encara si tenim en compte que el professor Joan Tusquets va definir el vell continent com «constant en la inconstància» (Tusquets, 1969, p. 460461). És clar que la controvèrsia i la lluita han facilitat la irrupció d'accions i moviments a 
favor de la unitat, amb la intenció de superar aquesta dialèctica de topades, sovint militars, que es remunta als presocràtics. En conjunt, tot plegat forneix un esperit de xoc, de combat i polèmica, que recorda el principi d'Heràclit, segons el qual tot és lluita, una confrontació que consumeix energies immenses i que ha produït tot tipus de desgràcies i violències.

Arribats a aquest punt, cal tenir en compte que a la primera edició dels Rencontres Internationales de Ginebra, celebrada al final de l'estiu de 1946, Rougemont deixava constància que l'home europeu -enfront de l'americà i del soviètic- és I'home de la contradicció, «l'homme dialectique par excellence», ja que es troba sempre entre dos pols: immanència i transcendència, individual i col-lectiu, obertura i tancament, liberalisme radical i afirmació dels valors de la comunitat, seguretat del món d'ahir i inestabilitat moderna, tot basculant ideològicament i política entre els Estats Units i la Unió Soviètica (Rougemont, 1946). Tant és així que una altra característica definitòria d'Europa és la tensió que es produeix entre la modernitat científica i tècnica i la incapacitat per a l'organització política de la vida col-lectiva, més enllà de l'estat-nació que després del mapa de 1918 dibuixat pel president Wilson, amb l'aparició de noves nacions, ha hagut d'enfrontar-se amb nous reptes com el federalisme en una esfera continental, que vol superar el sentiment nacional a fi de convergir en una consciència europea, sempre difícil d'afaiçonar (Corredor, 1971, p. 62-70).

Vistes així les coses, l'europeu és l'ésser de la contradicció, de manera que quan s'analitzen les arrels d'Europa, sorgeix aquest esperit dialèctic que es troba en el germen de la idea europea i, igualment, en la identitat de l'homo europaeus. Des d'aquesta perspectiva es proclama -tal com va succeir en els anys que van seguir a la Segona Guerra Mundial- una unitat espiritual continental, tal com es va fer evident en el volum primer de la col-lecció «Criterion», aparegut el 1959, sobre la unitat espiritual d'Europa. En aquells moments es destacava el paper del caputxí Antoni Verleye, fundador del Col-legi d'Europa de Bruges i del Centrum Ryckevelde de Sijsele (Bèlgica). Aquell conjunt de treballs aplegats sota el títol genèric de la unitat espiritual d'Europa, posava l'èmfasi en l'humanisme, que té per base l'hel-lenisme i la cultura llatina, sense deixar de banda el cristianisme que posa de relleu la centralitat de Crist que va morir per redimir els homes (Diversos autors, 1959, p. 42-43).

En aquell moment s'esmentava el paper d'Erasme de Rotterdam i de Joan Lluis Vives en la construcció de la vella Europa, alhora que el P. Basili de Rubí denunciava els perills d'una Europa material -basada en els principis de l'economia liberal-que oblidés aquest transfons espiritual. «Sembla que solament guiïn aquesta unió interessos d'ordre material, d'ordre econòmic» (Diversos autors, 1959, p. 43). En línies generals, es venia a dir que la idea d'Europa tenia una ànima inspirada en els valors del cristianisme que havien de fer possible el progrés material i el benestar per a tothom. Així s'expressava Ludwig Erhard -ministre d'economia amb Konrad Adenauer i canceller de la RFA entre 1963-1966- que, després d'haver estat el propulsor del miracle econòmic alemany en defensar el liberalisme sense proteccionisme ni aranzels, era conscient que calia no postergar, enllà dels factors econòmics, els designis espirituals. "La verdadera integración nos eleva, en lo espiritual, en lo moral y en lo psicológico, a un plano superior de colaboración» (Erhard, 1957, p. 261). Així, doncs, aquí trobem un altra antinòmia marcada per la tensió entre el progrés econòmic i els valors morals i socials. 
En aquest sentit, l'arrel religiosa d'Europa ha generat un debat encès, a partir de la consideració i valoració de l'aportació cristiana a la gènesi de la identitat continental. Per uns, i Madariaga (1951) va ser d'aquests, Europa és cristiana, com ho va ser per alguns dels seus progenitors com Monnet, Schuman i De Gasperi, un fet que Semprún va reconèixer quan va afirmar que «todos los inventores de Europa pertenecen al movimiento de la democracia cristiana»(Semprún, 2008 p. 17). Aquest rerefons cristià queda ben palès en filiació política dels primers líders europeus que es van afiliar a corrents afins a l'ideari de la democràcia cristiana que troba en el Partit Popular italià de Luigi Sturzo, que va actuar abans del feixisme, un innegable precedent des del moment que va reclamar una educació política, que a més de combinar el cristianisme amb la democràcia, s'oposava al totalitarisme d'estat. No debades, Sturzo va afirmar el 1938 que el feixisme -al igual que el nazisme- tendeix a la unificació i que «proposa una organització militar més que no pas un ideal de vida civil» (Gonella i Sturzo, 1961, p. 45).

No obstant, i al costat dels que veuen en la identitat europea la presència cristiana, hi ha aquells que manifesten que la idea d'Europa depèn de la Revolució Francesa amb el seu programa de fraternitat republicana (que mostra una innegable influència cristiana) i de la consciència social dels moviments obrers i sindicals dels segles XIX i XX, entre els que s'insereix el marxisme i, per extensió, la socialdemocràcia. Aquí, probablement sigui oportú esmentar el nom del socialista belga Paul-Henri Spaak, un dels que van posar els fonaments de la nova Europa (Martín de la Torre, 2015, p. 253-280). Tot amb tot, faltaríem a la realitat si negligíssim al nazisme, una de les manifestacions del totalitarisme, que amb la seva moral neopagana de senyors va voler imposar per la força una cosmovisió que s'enfrontava no només al liberalisme polític sinó també -i això és el més important pels nostres interessos- al cristianisme, si bé per raons antisemites va apuntar primer contra els jueus. En conseqüència, i per sorprenent que pugui semblar encara avui, la religió continua sent una qüestió disputada, tal vegada sense resoldre, que va tornar a sorgir quan es va discutir el preàmbul de la constitució europea en referir-se a les arrels cristianes del vell continent (Martín de la Torre, 2015, p. 13-14). En suma, aquí sorgeix una nova tensió al voltant de la presència cristiana en la configuració d'Europa, afirmada per uns i negada, o simplement proscrita, per uns altres.

En qualsevol cas, si donem per bona la tesi que darrera de la unitat espiritual europea es poden entreveure vestigis de la gran narrativa cristiana, és obvi que el luteranisme adquireix un gran relleu. D'una part, perquè s'ha vinculat -com va fer Max Weber l'any 1903- l'ètica protestant a l'esperit del capitalisme. D'altra banda, perquè com bé assenyala Charles Taylor podria ser que l'actual era secular postmoderna trobés en el luteranisme una causa ben pregona. Així es manifesta el pastor Víctor Hernández Ramírez en l'article «El significado de Lutero para una Sociedad post-cristiana», que s'inclou en aquest dossier i que té l'origen en la conferència que l'autor va impartir el 27 d'octubre de 2017, a la Facultat d'Educació de la Universitat de Barcelona, dins de la jornada de treball dedicada a «La Reforma de Luter i la transformació d'Europa». Amb la Reforma -apunta Víctor Hernández- el cristianisme es va diversificar, alhora que va trencar el caràcter d'encantament del món, amb la qual cosa es pot deduir que els vents reformistes es troben a les arrels de l'actual secularització de la societat. Dit amb altres paraules: la Reforma també constitueix una cara ben visible de la modernitat.

És hora de posar fi a aquesta presentació que no té altre objectiu que emmarcar en les corresponents coordenades històriques quin va ser el significat de la Reforma lute- 
rana, en el context d'una Europa d'ascendència cristiana que ha seguit una trajectòria amb tensions. Abans de cloure aquestes línies volem, emperò, remarcar un parell d'idees-força que ens han empès a tirar endavant amb aquest dossier. En primer lloc, la contribució de l'aportació del cristianisme en les bases culturals i pedagògiques de I'actual Europa. I en segon terme, la possibilitat de llegir la història del cristianisme com una veritable Paideia Christi, que sobre la base del concepte de persona, constitueix una narrativa de llarg abast. Si Werner Jaeger (1957) va interpretar la història dels grecs des de la perspectiva de la Paideia, i va plantejar la fusió entre el cristianisme primitiu i la Paidea hel-lènica (Jaeger, 1965), recentment el teòleg Jesús Pikaza -que ha topat més d'una vegada amb la cúria romana i l'Església catòlica oficial, per la seva obertura i disposició al diàleg interreligiós- ha presentat Crist com un educador i, el que no és menys important, el cristianisme com una gran aventura pedagògica (Pikaza, 2017). Comptat i debatut, som del parer que aquest dossier pot contribuir -si més no ho intenta- a què aquesta narrativa de llarga durada, que s'endinsa en el món semita i en I'univers greco-llatí i que s'ha mantingut gràcies al fil del cristianisme, que defensa la dignitat de I'home que ha estat fet a imatge de Déu (Gn 1:26-27), sigui una mica més nítida, tot i les tensions que marquen la trajectòria i el destí d'Europa sempre constant en la inconstància.

\section{Referències}

Corredor, J. M. (1971) De casa i d'Europa. Barcelona, Editorial Selecta.

Dawson, Ch. (1951) Situación actual de la cultura europea. Madrid, Ateneo.

Delgado, B. (2002) La educación en la reforma y en la contrareforma. Madrid, Editorial Síntesis.

Diversos autors (1959) Unitat espiritual d'Europa. Barcelona, Criterion [Núm. 1].

Diversos autors (2015) Europa: retrobar l'ànima. Barcelona, Fundació Joan MaragallQüestions de vida cristiana, núm. 253.

Erhard, L. (1957) Bienestar para todos. València, Fundación Ignacio Villalonga.

Fullat, O. (2000) «Europa com a feina i com a tasca», Temps d'Educació, 2000, p. 335-394.

Fullat, O. (2005) Valores y narrativa. Axiología educativa de Occidente. Barcelona, Publicacions i edicions de la Universitat de Barcelona.

Gonella, G. (1961) Unitat d'Europa; Sturzo, L. La crisi de la democràcia. Barcelona, Rafael Dalmau, editor.

Habsburgo-Lorena, C. (2011) «En un momento de crisis en Europa» en Otto de Habsburgo, El camino de Europa. Madrid, Encuentro, p. 253-259.

Jaeger, W. (1957) Paideia. Los ideales de la cultura griega. México, Fondo de Cultura Económica.

Jaeger, W. (1965) Cristianismo primitivo y Paideia griega. México, Fondo de Cultura Económica.

Letta, E. (2017) Hacer Europa y no la guerra. Barcelona, Península.

Márai, S. (2016) ¡Tierra, tierra! Barcelona, Salamanca (1 a ed. 2006).

Madariaga, S. (1951) Bosquejo de Europa. México, Editorial Hermes.

Martín de la Torre, V. (2015) Europa, un salto a lo desconocido. Madrid, Encuentro. 
Monreal Pérez, J. L. (2017) «La contribución de Philipp Melanchton, Praeceptor Germaniae, a la llengua y a la enseñanza. Entre la cultura humanista europea y la reforma alemana». Historia de la Educación, Revista interuniversitaria, 36, p. 207-228.

Pamparacuatro, J. (2008) «Aspectes i innovacions pedagògics de Port-Royal: la "logique ou l'art de penser" i la "Grammaire générale et raisonnée"». Temps d'Educació, 35, p. 139-168.

Pellicani, L. (1990) «Cultura política socialista y Europa», en Socialismo y cultura. Javea IV. Madrid, Editorial Sistema, p. 83-96.

Pikaza, X. (1996) Las religiones monoteístas: judaísmo, cristianismo, Islam. Madrid, SM.

Pikaza, X. (2017) Jesús educador. La escuela cristiana. Madrid, Editorial Khaf.

Rougemont, D. de (1946) L'esprit européen. Rencontres Internationales de Genève (Conférence du 8 septembre de 1946). Adreça: www.rencontres-intgeneve.ch/bibliotheque (consulta 22 de març de 2018).

Semprún, J. (2008) Pensar Europa. Barcelona, Centre de Cultura Contemporània.

Sugranyes de Franch, R. (1988) «Culturalment Catalunya ja és Europa», a Repte de Catalunya davant Europa. Barcelona, Fundació Dr. Lluís Vila d'Abadal, p. 7-19 [El text correspon a la conferència dictada el 26 de novembre de 1985].

Tusquets, J. (1969) «Las "constantes" pedagógicas de Europa», a VI Semana Internacional de Estudios Sociales. Barcelona, Instituto de Ciencias Sociales-Diputación de Barcelona, 1969, p. 455-462. 